\title{
Dysgenic Secondary Congenital Glaucoma (About 10 Cases): Experience of the Ophthalmology Department of CHU HASSAN II-Fez
}

Dr. Hind Saidi", Pr Fouad Chraibi, Dr. Ouail Hassimi, Dr. Sarah Ech-Cherif El Kettani, Pr Ahmed Bennis, Pr Meriem Abdellaoui, Pr Idriss Benatiya Andaloussi

Department of Ophtalmology, CHU HASSAN II-FEZ, Morocco

DOI: $\underline{10.36347 / \text { sjmcr.2020.v08i10.018 }}$

| Received: 05.08.2020 | Accepted: 13.08.2020 | Published: 29.10.2020

*Corresponding author: Hind Saidi

Abstract

Original Research Article

Congenital glaucoma secondary to anterior segment malformation is a rare pathology. The purpose of our study is to analyze the epidemiological and clinical aspects of children with secondary congenital glaucoma and to evaluate the therapeutic results of these patients. Over a period of 5 years, we reported ten eyes from six childrens who were treated all of them by trabeculectomy with mitomycin by the same operator. The middle age was 3,8 mounths with a sex ratio around 0,5 males per females. Bilateral glaucoma was found in $66 \%$ of cases. The average initial intra-ocular pressure was $22,5 \mathrm{mmHg}$, the average follow-up was 24 mounths with a total success of $23 \%$ and partial success of $40 \%$. The prognosis was worse for dysgenesic secondary glaucoma.

Keywords: pathology, clinical aspects, Congenital glaucoma, mitomycin.

Copyright $\odot 2020$ The Author(s): This is an open-access article distributed under the terms of the Creative Commons Attribution 4.0 International License (CC BY-NC 4.0) which permits unrestricted use, distribution, and reproduction in any medium for non-commercial use provided the original author and source are credited.

\section{INTRODUCTION}

Congenital glaucomas are a set of pathologies from which we can distinguish an isolated primary form and secondary forms associated with dysgenesis of the anterior segment.

The purpose of this paper is to analyze the epidemiological and clinical aspects of children with secondary congenital glaucoma and to evaluate the therapeutic results for this group of patients.

\section{MATERIALS ANd MethodS}

Our series a retrospective study of cases of secondary congenital glaucoma which were operated on and followed up in our department over a period of 5 years. Epidemiological and clinical data including transparency, corneal diameters, preoperative and postoperative intraocular pressures were assessed.

Total success was defined as final postoperative intraocular pressure less than $15 \mathrm{mmHg}$ without associated medical treatment.

Partial success as postoperative intraocular pressure less than $15 \mathrm{mmHg}$ with associated medical treatment.

\section{RESULTS}

Ten eyes from six children were reported with a mean age of 3.8 months at diagnosis with a sex ratio of 0.5 . Consanguinity was present in all cases with a bilaterality of $66 \%$.

Two cases presented with Axenfeld-Rieger syndrome, two other cases with Peters syndrome and two cases with aniridia (Figure 1). The mean initial eye pressure was $22.5 \mathrm{mmHg}$.

All the children underwent a trabeculectomy with Mitomycin C and revision surgery in $70 \%$ of cases by the same operator. The average follow-up was 24 months with total success estimated at $23 \%$ and partial at $40 \%$ (Figure 2). The mean intra-ocular pressure at the last check-up was $15.8 \mathrm{mmHg}$. 


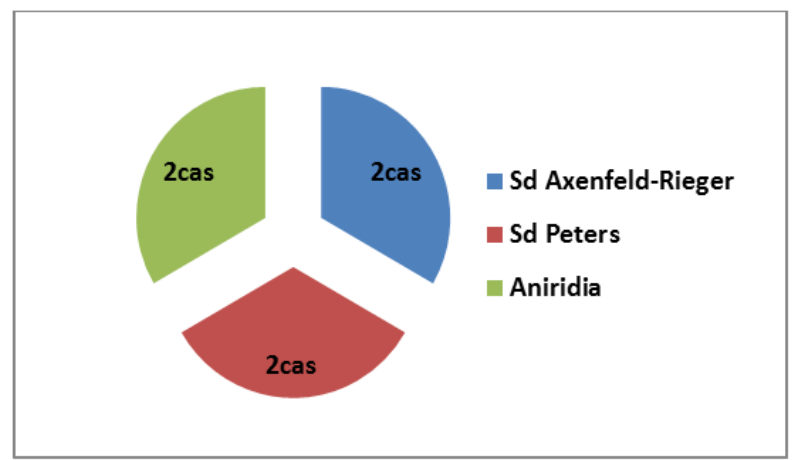

Figure-1: Distribution of cases according to etiology

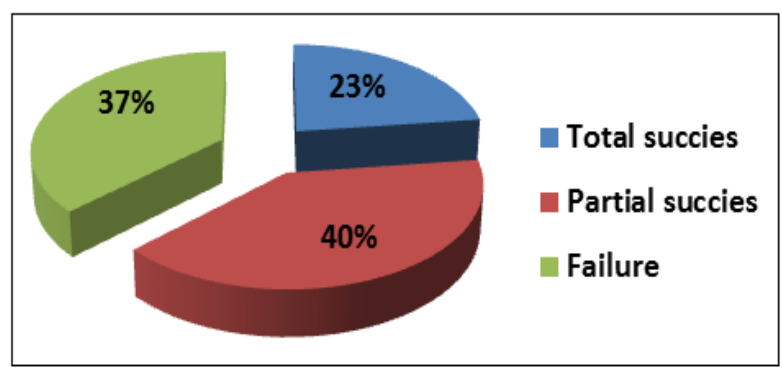

Figure-2: Thérapeutic results

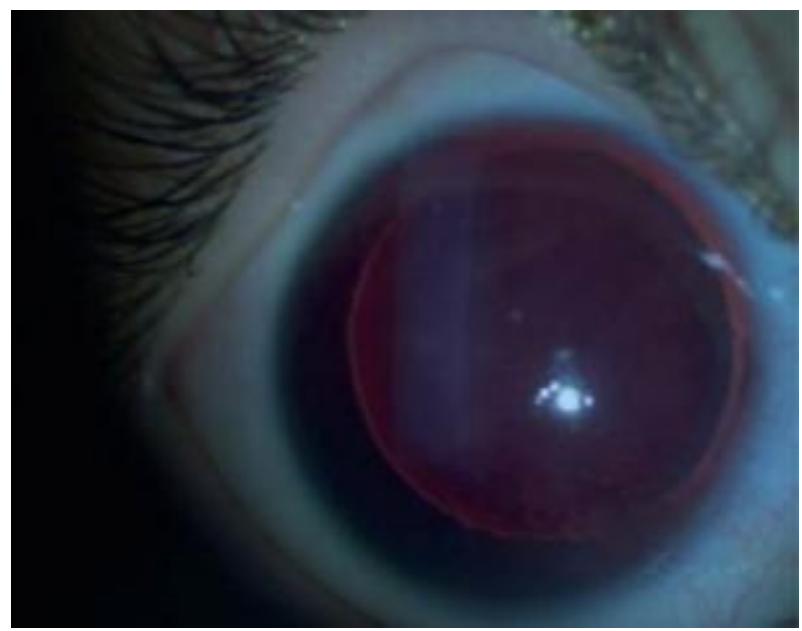

Fig-3: Total aniridia with iris aplasia

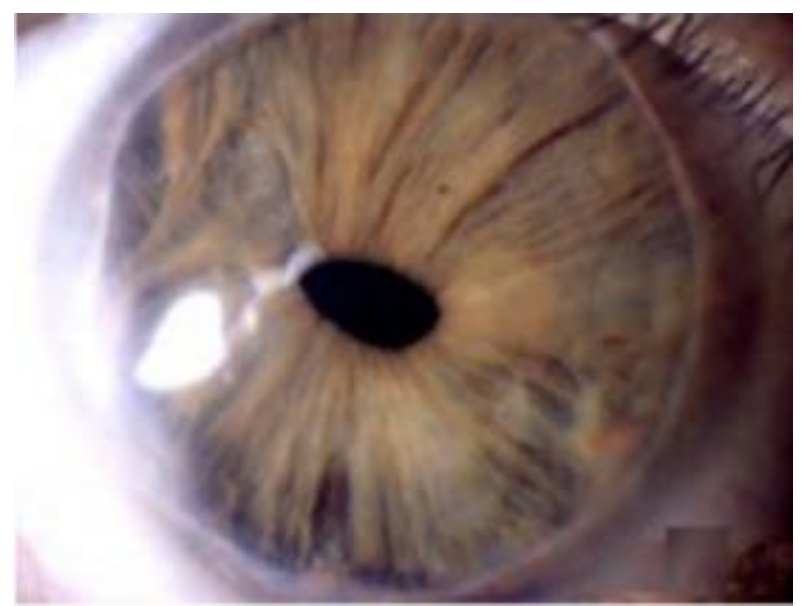

Fig-4: Posterior embryotoxon : Anexfield anomaly

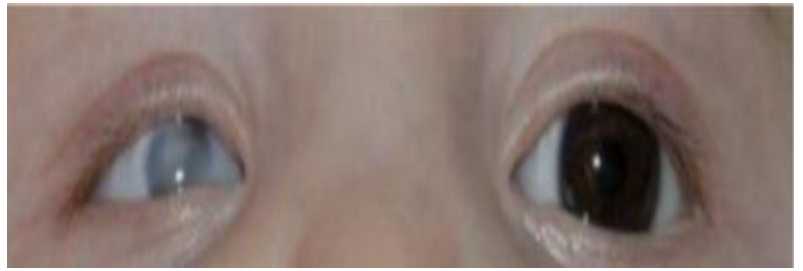

Fig-5: Peters syndrome: microphtalmia and corneal opacity

\section{DISCUSSION}

Secondary congenital glaucoma are rare affection and is often bilateral in about $80 \%$ of cases [1].

The mechanisms of formation of the anterior segment and their anomalies lead to different clinical forms [2]:

- Irido-trabeculodysgenesis is an abnormality of the angle and iris, often accompanied by glaucoma. A distinction is made between Axenfeld-Rieger syndrome and aniridia.

- Irido-corneo-trabeculodysgenesis is an abnormality of the angle, iris and cornea, often accompanied by glaucoma. A distinction is made between Peters syndrome and sclerocornea.

The treatment of secondary congenital glaucoma is essentially surgical. The more severe the malformation, the greater the risk of surgical failure, requiring iterative procedures [3].

In congenital dysgenic or secondary glaucoma, long-term results are poorer and normalization of intraocular pressure is short-lived probably due to the frequent association of pretrabecular developmental lesions [1].

Comparing the results of this group with the results of the study previously carried out in our department for primary congenital glaucoma over the same period, we note a lower success rate for the secondary congenital glaucoma group of $63 \%$ compared to $87.3 \%$ [4]. The literature also shows a lower success rate for this group of patients, which is consistent with our data [5].

\section{CONCLUSION}

The diagnosis of secondary congenital glaucoma must be established as early as possible with urgent treatment. There are no official recommendations regarding the management of this pathology and there are large differences according to the healthcare teams. This study shows the particular profile of secondary congenital glaucomas and their rarity as well as a probability of success significantly lower compared to the primitive forms. 


\section{REFERENCES}

1. Dureau P. Glaucomes congénitaux et trabéculodysgénésies: aspects cliniques et génétiques. Journal français d'ophtalmologie. 2006 Feb 1;29(2):198-215.

2. Bui Quoc E, Costantini E. Glaucomes congénitaux -2011 Elsevier Masson.

3. Lise-Schneider B, Calvas P, Roche O, Lambert JC, Dufier JL, Costet-Fighiera C. Glaucome secondaire à une aniridie et glaucome congénital isolé dans une même fratrie: apports et limites de la génétique. Journal français d'ophtalmologie. 2007 Jan 1;30(1):44-8.

4. Hassimi O. Les glaucomes congénitaux: Expérience du service d'ophtalmologie du chu Hassan II de Fès (A propos de 77 yeux). Thèse présentée et soutenue en 2018.

5. Denis D, Pommier S, Coste R, Fogliarini C, Benso C, Cornand E. Glaucome congénital et sclérectomie profonde: résultats d'une étude sur plus de 3 années. Journal français d'ophtalmologie. 2008 Feb 1;31(2):173-9. 